\title{
MONETARY POLICY AND CAPITAL FORMATION
}

$$
\text { Jai-Hoon Yang* }
$$

The year 1776 gave birth not only to a great nation but also to a great book which shaped our science. In his Wealth of Nations, Adam Smith made growth in income the central explanandum of his inquiry and identified capital formation as the prime mover of growth in income. It is most fitting, therefore, that the subject matter of this conference in this bicentennial year of the Wealth of Nations is capital formation.

I do not believe, however, that the theme of this conference was chosen merely, or even primarily, to commemorate the bicentennial of the locus classicus of our science. The choice of the theme reflects, I believe, the widely held concern about the adequacy of capital formation. ${ }^{1}$ The precise nature of the sources and significance for monetary policy of such concern, however, does not appear to be well delineated. Accordingly, the purpose of this paper is to provide a diagnosis of the sources of such concern and what such concern implies for the conduct of monetary policy.

\footnotetext{
$1_{\text {For an expression of "official" concern, see Economic Report of }}$ the President, January, 1976, pp. 34-47. For a summary of diverse views, see the Introduction by Eli Shapiro and William L. White to Capital For Productivity and Jobs, edited by E. Shapiro and W. White (forthcoming, Prentice-Ha11).
}

*Dr. Yang is an economist at The Federal Reserve Bank of St. Louis. The views expressed in this paper are those of Dr. Yang. 
The first section of the paper identifies the three analytically separable sources of the widespread concern about the adequacy of capital formation. The sources of concern are organized along the traditional dual roles that capital formation (or investment) play in augmenting productive capacity and generating income. The second section frames the issue associated with capital formation in an explicit intertemporal utility maximization paradigm. In such a paradigm, the issue of how, or even whether, to specify an aggregate utility functional looms paramount. The third section explores the possible role monetary policy may play in deepening the steady state capital intensity. This section draws liberally upon neoclassical monetary growth theory and the theory of money bearing on the technology of exchange.

Monetary policy would serve the cause of capital formation best by being directed toward the attainment of full capacity output. The implications of such a thrust of policy for the knowledge required to define an appropriate monetary policy will be considered later. A catalogue of unresolved issues is provided whose resolution is essential for improving the quality of advice given to the monetary policymakers. Much attention is devoted, in this section, to the different concepts of stabilization policy and the feasibility of discretionary stabilization policies. In the concluding section, the optimum monetary policy, in a world of costly information and possible "coordination failures," is identified as one which is systematically free of 
policy innovations. 2 Such a "surprise-free" policy regime would minimize the risk of superimposing policy-induced shocks on non-policy shocks and enable the homeostatic capacity of the price system to respond more effectively to the changes in the non-policy sources of shocks. A brief discussion of the appropriate empirical proxy for such an ideal monetary policy concludes the paper.

\section{Sources of Concern: A Diagnosis}

The widespread concern with the recent and prospective pace of output growth and capital formation appears to have three analytically separable sources. The first source of concern is the possibility of not attaining capacity (full equilibrium) output. This failure may be attributable either to the emergence of a capital shortage-labor surplus economy (to be defined) due to the "putty-clay" nature of the capital stock, or to the emergence (and persistence) of an unemployment state due to the standard effective demand failure. Here the focus is on the income and employment generating function of investment, or with the role of capital formation in attaining the full employment objective.

How can the "putty-clay" nature of capital stock induce the emergence of a capital shortage-labor surplus economy? One can always explain such a possibility by resorting to the Keynesian labor supply function. A temporary excess supply of labor, or its dual, capital

\footnotetext{
"For the concept of "coordination failures," see Axel Leijonhufvud, "Effective Demand Failures," Swedish Journal of Economics, 701.75 (1973).
} 
shortage, would emerge in response to a reduction in the capital stock, as such a reduction decreases the demand for labor. ${ }^{3}$ of course, such a phenomenon would not persist unless the price level and the relative rental prices of factors do not adjust to eliminate the implied notional, excess demand for commodities. ${ }^{4}$ However, in a putty-clay world, one does not have to resort to this trivial Keynesian case. One gets the same theoretical result even with a classical labor supply function. The decline in the demand for labor (consequent to the reduction in the capital stock) in conjunction with fixed factor proportions in a Cobb-Douglas world would yield such a result. ${ }^{5}$ The key point to remember is that in such a world, the marginal product of labor is a function only of factor proportions and, hence, even in the

${ }^{3}$ Such a reduction in the capital stock may be induced by war or by an accelerated capital obsolescence or abandonment induced by unexpected changes in the relative prices of factor inputs, such as the energy input. In a putty-putty world, capital obsolescence, of course, could not occur.

${ }^{4}$ For the concept of notional excess demand, see R. Clower, "The Keynesian Counterrevolution: A Theoretical Appraisal," in The Theory of Interest Rates, edited by $F$. Hahn and F. Brechling (London: Macmillan \& Co., Ltd., 1965).

${ }^{5}$ For theoretical discussions of the possible emergence of the unemployment state due to a shortage of capital in a putty-clay world, see Kenneth J. Arrow, "The Economic Implications of Learning by Doing," Review of Economic Studies (June 1962) and Leif Johanson, "Substitution versus Fixed Production Coefficients In the Theory of Economic Growth: A Synthesis," both reprinted in Readings in the Modern Theory of Economic Growth, edited by J. Stiglitz and H. Uzowa (M.I.T. Press, 1969); also R. Eckaus, "The Factor Proportion Problems in Underdeveloped Areas," American Economic Review (September 1955). 
presence of an excess supply of labor, the real wage would not decline! The long-run adjustment would entail augmenting or replacing the capital stock with a capital stock embodying different technology.

A second source of concern with capital formation arises from its capacity-augmenting function. It derives from dissatisfaction with the full equilibrium capacity growth path generated by the decentralized market process. Here the actual (or prospective) capacity growth path is compared to some desired growth path. The determination of such a desired growth path may be based on some implicit criteria or, more formally, on the solution values of a full-blown multiperiod optimization problem involving the Ramsey-type functional, 6

$$
\int_{0}^{T} u_{t}(c, t) d t=\int_{0}^{T} F_{t}(k, \dot{k}, t) d t
$$

The market-determined growth path is often judged to be suboptimal or inconsistent with the target path, even when full employment is continuously maintained. Myopia, identified by Pigou as "defective telescopic faculty," is often singled out to explain why the marketdetermined equilibrium capital intensity stops short of the desired (deeper) capital intensity. The capital intensity associated with the

${ }^{6}$ For Ramsey Economics concerned with optimal economic growth, see S. Chakravarty, Capital and Development Planning, especially Chapters I - IV (M.I.T. Press, 1969) and the forward by Paul Samuelson; also M. Intrilligator, Mathematical optimization and Economic Theory, Chapter 16 (Prentice-Haר1, 1971). For a discussion of a functiona1, which defines a real number for any given function defined over a domain, see R. G. D. Allen, Mathematical Analys is for Economists (St. Martin's Press, 1934). 
golden rule of accumulation may be identified as the target intensity. ${ }^{7}$ In this paradigm, the "required" policy actions are envisioned as steering the economy toward a higher growth path of consumption at a cost of reduced consumptions during the transition periods. Given the impossibility theorem of Arrow regarding the derivation of consistent aggrew gate preference orderings, it is clear that the choice of the utility functional to be maximized poses a fundamental challenge to the solution of this "inappropriate equilibrium capital intensity" problem. The recent "capital shortage" controversy may be interpreted in this context as expressing the concern about the adequacy of saving to finance the "required" capital formation. The primary concern is about the potential "savings gap" as opposed to the (Keynesian) concern about the "investment gap" touched upon earlier. 8

7 Along the golden rule balanced growth path, consumption per capita is maximum. See E. Phelps, "The Golden Rule of Accumulation," American Economic Review (September 1965) and J. Robinson, "A Neo-classical Theorem," Review of Economic Studies (June 1962).

${ }^{8}$ There are two diametrically opposed approaches to viewing aggregate capital formation from a longer-run perspective. One is that of "optimization" or "utility-maximization" approach. Under this approach, aggregate capital formation is viewed as endogenous, that is, as the outcome of deliberate life-cycle consumption decisions made by the individual spending units in the economy, given their tastes and perceived market and productive opportunities. In this approach, the choice of future consumption paths and the current investment decisions are jointly and simultaneously made. The other approach is the "consistency" or "planning" approach. This approach under]ies the recent concern for "capital shortage." Under this approach, the choice of a future consumption (and growth) path is made outside the market process, presumably by reference to some collective preference ordering. The "required" capital formation is then computed to achieve such a path. The concern for capital adequacy in this context is really for the concern for the potential "saving gap" to achieve the "required" capital formation and such a concern can arise only under the consistency (continued) 
The third source of the recent concern with capital formation appears to be associated with the general realization that the size of current and prospective capacity output has fallen short of what was expected. This shortfall is due partiy to those measures, such as increased regulatory constraints which tend to increase the capital-output ratio, and partly to those events, such as an increase in the relative price of energy, which accelerated obsolescence of existing capital stock.

The problem posed by this discovery appears to be essentially the same as the one associated with the second source discussed above. In both cases, capital formation is viewed as a problem involving intertemporal utility maximization by reshaping the time path of consumption. However, the urgency with which the problem is viewed may differ, inasmuch as the growth path is perceived to be permanently lower than that which was taken for granted earlier, in the absence of redoubled efforts at capital augmentation.

Intertemporal Choice and Equilibrium Capital Intensity

The concern for capital formation is a derived concern, that is, a concern derived from the desire to achieve a fulter utilization of scarce resources over time and/or to alter the time-shape of consumption flows, given the full resource utilization rates. The mode of analysis

\footnotetext{
8 (continued)

approach. For the distinction between the optimization and consistency approach, see Chakravarty, op. cit., pp. 7-10; also K. Fox, J. Sengupta and $\mathrm{E}$. Thorbecke, The Theory of Quantitative Economic Policy (NorthHolland, 1973), pp. 448-449 and 465-466.
} 
implied by the latter concern is necessarily intertemporal in character and collectivist in orientation. One posits an existence of an instrumentality, such as the state, through which public choice regarding the desired capital intensity is to be implemented. The objects of choice in this intertemporal decision framework are different consumption paths over time associated with different transformations of dated consumption options. 9

From the constraints in this multiperiod decision problem, e.g., the initial endowments of resources, the expected technology of production and exchange and other initial conditions, one can in principle derive the feasible objects of choice. Abstracting from inevitable uncertainty, and possibly from the Strotz paradox as well, a choice which maximizes a utility functional may, in principle, be made. ${ }^{10}$ At this level of abstraction, all of the information required to define a set of technologically feasible consumption paths is assumed to be available without cost. Should a well-defined utility functional be available, except for the purely computational costs involved, the decision problem becomes trivial.

${ }^{9}$ For a modern extension of Irving Fisher's seminal work on investment viewed as a problem in intertemporal utility maximization, see $\mathrm{J}$. Hirshleifer, Investment, Interest, and Capital, (Prentice-Ha11, 1970).

10 The Strotz paradox or phenomenon refers to the possibility that, even with perfect foresight, time perspective at any point in time distorts the choice of a consumption path over a time horizon in such a way that either the choice is revised or an occasion for regret arises subsequentiy. See R. Strotz, "Myopia and Inconsistency in Dynamic Utility Maximization," Review of Economic Studies (Vol. XXIII, No. 62, 1956); Chakravarty, op. cit., pp. 41-45; also R. Pollak, "Consistent Planning," Review of Economic Studies (April 1968). 
The principal policy problem in such a full-information world is to define a collective preference ordering function over alternative full capacity consumption paths. In the event that the optimum consumption path so chosen differs from the market-generated path (evolving along a capacity path), the intertemporal resource allocation decisions will be centrally directed. Since, by assumption, the only argument appearing in the preference functional is the alternative consumption paths, the conflict over centralized direction and decentralized market direction of resource use does not arise in this paradigm. However, a question regarding the appropriate time horizon remains even at this level of abstraction inasmuch as the choice of any particular consumption path over a given horizon restricts the set of consumption possibility paths beyond the chosen horizon. It does this by predetermining the initial conditions in the future.

Underlying this view of optimal consumption choice over time are various strands of nonmonetary (optimal) growth theories. ${ }^{11}$ Different rates of capital accumulation are associated with different equilibrium capital intensities and growth paths of income and consumption. However, along the balanced growth paths where capital intensities remains constant, growth rates of income and consumption remain invariant to the rate of capital accumulation. In the study of such comparative dynamics, it is generally assumed that full employment is obtained uniformly; the

${ }^{11}$ For a survey of such theories, see F. Hahn and R. Matthews, "The Theory of Economic Growth: A Survey," Economic Journa1, (December 1964); also H. Wan, Economic Growth (Harcourt Brace Jovanovich, Inc., 1971). 
focus of analysis is on the consequences of different consumption-saving/ investment decisions on the steady state paths of levels in income and consumption. A1though the focus is generally on the characteristics of the steady state paths, the explicitly intertemporal framework enables considerations of such questions as (1) the feasibility of attaining a particular path such as the Golden Rule path via the competitive process and (2) the appropriateness of considering only the steady state values, but not the transient values, of consumption in devising growth policies. For example, it is now well known that a competitive solution may yield inefficient steady state paths should the rate of interest fall short of the rate of growth due to excessive capital deepening. ${ }^{12}$

The Nonneutrality of Money and Monetary Policy in the Long-run

The preference for a market-determined solution to the intertemporal resource allocation problem is yet another strand characterizing (optima1) growth theories. Such a preference is based on various efficiency and equity considerations. Accordingly, to deal with the question of whether the introduction of money alters the market-determined balanced growth path, money is introduced explicitly into growth theories both as a medium of exchange and a store of value. ${ }^{13}$

${ }^{12}$ See, for example, P. Samue1son, "An Exact Consumption-Loan Model of Interest With or Without the Social Contrivance of Money, "Journal of Political Economy (December 1958); P. Diamond, "National Debt in a Neoclassical Growth Model," American Economic Review (December 1965) and D. Cass and M. Yaari, "Individual Saving, Aggregate Capital Accumulation, and Efficient Growth," in Essays on the Theory of Optimal Economic Growth, edited by K. Shell (MIT Press, 1967).

${ }^{13}$ See Samue1son, op. cit., pp. 481-482; J. Tobin, "Money and Economic Growth," Econometrica (October 1965); J. Stein, Money and Capacity Growth (Columbia University Press, 1971). 
When the issue is joined in terms of comparative dynamics involving two economies, identical in every aspect but for the use of money, there is not likely to be much dispute about the nonneutrality of money, even in the long run. For example, with the social contrivance of durable money, the real rate of interest cannot be driven below zero with stationary or growing population. This fact alone will help forestall the emergence of inefficient steady state path, which is a logical possibility in some intergenerational consumption-loan models. ${ }^{14}$ However, there are likely to be as many different explanations for such nonneutrality as there are different diagnoses of the essential differences between money and barter economies.

The concept of the nonneutrality of money considered above is fundamentally different from that of the nonneutrality of monetary policy in the long run, given an on-going money economy. Here, monetary policy is to be construed broadly as a vector of actions which results in the differential growth rates in the nominal money stock. There is as yet no consensus in the answer given to the question of nonneutrality of monetary policy in the long run because the question regarding the effect of monetary policy on equilibrium capital intensity is unresolved.

The much-debated classical dichotomy appears to rule in favor of neutrality of monetary policy in the long run. However, under the classical paradigm, the neutrality of monetary policy is obtained under a specialized monetary policy regime, which insures portfolio balance at a stable price level. To clarify this statement, consider the usual

${ }^{14}$ See, for example, Samuelson, op. cit. 
comparative static analysis of the effect of a one-shot change in the quantity of the nominal money supply on real variables of the stationary economy. The steady state values of the real variables, including the real balances per capita, remain invariant. At the new equilibrium, after the initial disturbance, the price level is higher but constant. The cost of holding real balances, therefore, remains unchanged and hence the equilibrium quantity of real balances held is unchanged. Consider now an alternative monetary policy which engineers a maintained increase in the nominal money supply at some constant rate. To the extent such a policy generates an expectation of inflation, the cost of holding real balances will rise and the initial portfolio balance will be disturbed. Whether this policy would induce a change in the equilibrium capital intensity is an open question. The same type of considerations are involved in the analysis of comparative dynamics of an economy growing steadily at the natural rate of growth.

Some tentative answers may be given to the question of the nonneutrality of monetary policy in the long run. In the event that the rate of increase in the nominal money supply is greater than the natural rate of growth, neoclassical monetary growth theories (characterized by the absence of an independent investment function and the presence of real wealth effect in the saving function) obtain capital deepening. The mechanism by which this nonneutrality is obtained, for a monetary policy which induces a non-zero rate of equilibrium inflation rate, is known as the inverse wealth-saving relationship. A consensus appears to have emerged on the theoretical foundation of the wealth-saving relationship Anduced by changes in monetary policy: both the change in $x$, the rate 
of growth of the nominal money supply, relative to the rate of growth in output and also the way such a change in $x$ is engineered are crucially important in determining the neutrality of monetary policy. ${ }^{15}$

In Metzler's exploration of the question, he obtained a "heretical" result of nonneutral monetary policy even in the context of fully employed stationary economy. ${ }^{16}$ The conclusion he drew from the analys is was that a one-shot open market operation altered (lowered) the equilibrium interest rate, even though the price level was unchanging in the new equilibrium, albeit at a higher level. Real balances in the new equilibrium were greater than in the initial equilibrium. ${ }^{17}$ This nonclassical result is due to the capital levy aspect of the operation (analogous to an increased budget surplus), rather than being due to pure monetary policy operation. ${ }^{18}$ For example, such a pure monetary policy action as a once-and-for-al1 money injection through government transfers is not expected to alter the solution values of real variables.

${ }^{15}$ For a survey of extensive 1 iterature in this area, see A. Meltzer, "Money, Intermediation and Growth," Journal of Economic Literature (March 1969); also Stein, op. cit., pp. 21-22.

16L. Metzler, "Wealth, Saving and the Rate of Interest," Journal of Political Economy (April 1951).

${ }^{17}$ This conclusion on the new equilibrium real balances is not the one reached by Metzler himself. It is inferred from his conclusion about the lower equilibrium (real) interest rate and his assumption of fully employed economy. An additional assumption that the demand for real balances is invariant to the level of private real wealth is sine qua non.

${ }^{18}$ See MeTtzer, op. cit., p. 28. 
Such a policy would result in a once-and-for-all increase in the price level but would affect neither the equilibrium real wealth, including the real balances, nor the equilibrium market and real interest rates. In contrast, a pure monetary policy designed to permanentiy increase the growth rate in nominal money relative to that of output has a nonneutral, positive effect on the capital intensity in the Tobin-type Neoclassical monetary growth models. ${ }^{19}$ In such models, the deepening in the equilibrium capital intensity is obtained through the following mechanism: (1) an increase in the anticipated rate of inflation engineered by a well-publicized permanent increase in the rate of monetary expansion increases, through the Fisher effect, the market interest rate; (2) the entailed increase in the cost of holding real balances reduces the equilibrium amount of real balances; (3) the fall in real wealth occasioned by the reduction in real balances increases the rate of saving and the rate of capital formation through the posited inverse wealthsaving relationship. The capital deepening and a lower real rate of $i n-$ terest are the results.

The logic of this line of thought points to the implementation of an accelerated target rate of anticipated inflation if accelerated capital formation is desired. This intuitively anomalous result stems from the

${ }^{19}$ The conclusion holds only for an on-going monetary economy. Relative to a barter economy, a monetary economy has a lower capital intensity in the Tobin-type Neoclassical monetary growth models. Such modeis are characterized by the absence of an independent investment function and the presence of real balances in the saving function. See Tobin, op. cit., and Stein, op. cit., pp. 6-9, 33-34 and 47-48; also M. Sidrauskis, "Inflation and Economic Growth," Journal of Political Economy (December 1967). 
invalid use of ceteris paribus. Systematic destruction of real money capital occasioned by the increased expected rate of inflation in the model merely shifts preferences regarding wealth portfolio composition, without affecting the attainable global production frontier. Money plays no real productive role in the model. Money is nonneutral only in the sense of altering the preferred asset compositions but very much neutral with respect to the attainable or "effective" global production possibility frontier.

Money, however, is a productive asset (i.e., it affects the attainable production frontier) fundamentally because, by reducing transactions cost, it increases the scope for division of labor. Derived financial innovations based on the existence of money, in the form of primary and indirect securities, further the extent of division of labor. Increased degree of specialization moves outward the attainable production frontier because the distribution of resource ownership and productive opportunities happen to be in general "non-coincident." From this perspective of the role of money in the technology of exchange, then, any attempt to promote capital deepening by engineering a programmed anticipated inflation must be judged quixotic.

What would be the effect of the open market operations of the type the central bank engages in, whereby the non-interest bearing base money is exchanged for interest bearing government debt? Whether or not an open market operation has a nonneutral effect on the equilibrium capital intensity and growth path depends crucially on the extent of tax discounting (the capital levy aspect) and upon whether the operation is part of a plan to permanently change the growth rate in money relative 
to the growth rate in output.

With perfect discounting of future tax liabilities associated with interest bearing government debt, i.e., government bond is not a part of private net wealth, and a one-shot open market purchase, the effect on the equilibrium capital intensity would be as negligible as in the previous case where once-and-for-all increase in the nominal money stock was brought about by pure goverment transfers. In the event that tax discounting is imperfect, a one-shot open market purchase would be equivalent to the Metzler's capital levy case. In the event the open market purchase is part of a well-publicized program to engineer a change in the rate of anticipated inflation, such an attempt to induce capital deepening by monetary acceleration would again appear to be quíxotic.

The two analytically separable questions regarding nonneutrality may be restated as:

(1) Does money matter in the long run?

(2) Does monetary policy matter in the long run?

The answers considered above in terms of the prevaliting paradigms of comparative statics and comparative dynamics are atemporal. They deai only with the steady state solutions. Given that the objective of monetary policy is the optimization of a given objective functional over the relevant policy horizon, there is no presumption that the choice anong the various policy options can be based solely, or even primarily, upon the characteristics of the steady state solutions. Nor is there any presumption that the focus should be on the characteristics of transient response to the chosen monetary policy action. The explicit inter- 
temporal choice framework indicates that the policynaker must assess the characteristics of both the transient and steady state responses of the economy to the chosen policy action.

The above way of viewing the elements of an optimum policy appears to make the requirements for such a policy stringent, However, such a characterization is itself an oversimplification in the following fundamental sense: it implicitly assumes that a policymaker has reliable information about the past evolution and current state of the economy. That is, it is assumed that the characteristics of the initial conditions are known and the requirements for observability are met. 20 In the absence of such assumptions, the recent history of shocks to the system to which the economy has not yet fully adjusted, must be identified and allowed for in assessing the likely evolution of the economy, both with and without the contemplated policy action. In addition, the behavioral parameters of the model are implicitly assumed to be timeand policy-invariant. To the extent such assumptions do not hold, the efficacy of any policy action chosen on the basis of the projection of such a model will be attenuated.

20 In control system theory, observability or reconstructibility refers to the property of the model which enables one to determine unique$1 y$ the past states of the system from a set of currently available observation data. See M. Aoki, Optimal Control and System Theory in Dynamic Economic Analys is (North-Holland Publishing Company, 1976), pp. $108 \mathrm{~m} 11$. 


\section{Is There a Role for Monetary Policy In Promoting Capital Formation?}

Perusal of the recent literature dealing with the capital formation problem indicates that the focus placed on monetary policy is primarily from the perspective of nonneutrality of monetary policy in achieving the full capacity output. ${ }^{21}$ The question regarding the nonneutrality of autonomous monetary policy on equilibrium capital intensity is seldom raised explicitly in a policy context. The role designated for monetary policy, in achieving the full capacity output, is typically an accommodative one of keeping the market interest rate from rising, while a stimulative fiscal policy, such as accelerated depreciation and investment tax credit, is undertaken to promote investment. ${ }^{22}$

The debate concerning the efficacy of such a policy revolves around different assessments of its likely effects. In the first instance, the debate is an empirical one arising from the absence of reliable or consensus scenarios for the evolution of the economy under alternative policy regimes. Also absent is a consensus reading of the true state of the economy. For example, is the underutilization of capital stock as widespread as the measured capacity utilization rates indicate? ${ }^{23}$ If

${ }^{21}$ See, for example, B. Bosworth, "The Issue of Capital Shortages," and R. Eisner, "The Corporate Role in Financing Future Investment Needs," both in U.S. Economic Growth From 1976 to 1986: Prospects, Problems and Patterns, Vol. 3 - Capital, Studies prepared for the Joint Economic Committee, U.S. Congress, November 15, 1976, and the works cited therein.

${ }^{22}$ See, for example, A. Brimmer and A. Sinai, "The Effects of Tax Policy on Capital Formation," Journal of Finance (May 1976).

${ }^{23}$ Since this passage was written, the Federai Reserve Board published a substantially revised series on capacity utilization rates. The utilization rate for the third quarter 1976 was revised upward seven percentage points, from 74 to 80.9 percent. 
the numbers are to be believed, would not policies designed to increase capacity utilization rates directly be more likely to be more effective in inducing investment than the policies designed to reduce the rental price of capital? If, on the other hand, the numbers are regarded as having substantial downward bias because of the underestimate of the extent of capital obsolescence (due to increases in relative price of energy, and more stringent regulatory requirenents), would not policies designed to stimulate investment be more effective than otherwise? ${ }^{24}$

Related uncertainty about the extent of policy effects on capital formation emanates from our incomplete knowledge about the effect of expectations on the way market participants perceive and respond to a policy measure. There appears to be an emerging consensus that the prevailing state of expectations plays an important role in shaping the response to certain policy measures. However, a successful modeling of the formation and revision of expectations (policy, price, income, etc.) has been elusive. Consider, for example, the problem of assessing the relative merits of interest rates and monetary aggregates as the targets of monetary policy. Recent analysis by Sargent and Wallace shows that Poole's apparentiy sensible results, that the choice depends on the structural parameters and the covariance structure of the disturbance terms, are conditional upon the implicit acceptance of the adaptive

\footnotetext{
${ }^{24}$ For an analysis which adduces significant indirect evidence corroborating the view that there is such a downward bias, see $D$. Karnosky, "The Link Between Money and Prices - 1971-1976," Review, Federal Reserve Bank of St. Louis (June 1976).
} 
expectation hypothesis. ${ }^{25}$ Should expectations be generated rationally, Poole's results no longer hold.

Even when it is granted that our reading of the current state of the economy is accurate, i.e., that there is widespread, persistent unemployment of both capital and labor, we cannot formulate an appropriate policy in the absence of a correct diagnosis of the causes of such persistent unemployment. It would not be enough to single out deficient aggregate demand as the proximate cause, even if it were true. What is required is an analysis of how such a deficiency emerged and why it persists.

For example, consider Leijonhufvud's interpretation of Keynes' diagnosis of the root cause of the Great Depression. The persistent deficiency in aggregate demand was diagnosed as reflecting the "co-ordination failure" between the saver and the entrepreneur, due to a "Tow" price of capital goods relative to money wages. ${ }^{26}$ In the latter phase of the Depression, this "low" price was due to the pessimistic state of entrepreneurial expectations. An implied policy prescription was fiscal policy a outrance, with an accommodative monetary policy, desiqned to

${ }^{25}$ W. Poole, "Optimal Choice of Monetary Policy Instruments In a Simple Stochastic Macro Model," Quarterly Journal of Economics (May 1970); T. Sargent and N. Wallace, "Rational Expectations, the Optimal Monetary Instrument and the Optimal Money Supply Rule," Journal of Political Economy (April 1975).

${ }^{26} \mathrm{~A}$. Leijonhufvud, On Keynesian Economics and the Economics of Keynes (Oxford University Press, 1968), p. 409. 
falsify the inappropriate entrepreneurial expectations. In the earlier phase of the downturn, it was based on a "high" market interest rate, that is, a market rate higher than wicksell's natural rate, not the state of entrepreneurial expectations. Monetary policy à outrance would have been the prescribed response to bring the market rate down to the natural rate. 27

The following diagnosis of the causes of the current malaise is consistent with the relative price interpretation presented above. The initiating cause was the totally unforeseen reduction in the nation's wealth (productive capacity) occasioned by the rise in energy prices and various regulations. The implied reduction in capital intensity would cause a rise in the marginal productivity of capital and lower the real wage of the Tabor in a world of malleable capital. However, in a world of putty-clay capital, the downward adjustment of the real wage is delayed and follows the replacement investment of vintage capital as well as inter-industry shifts in employment. Further, since the initial reduction in wealth and increased uncertainty regarding income and employment prospects induces increased rate of saving, aggregate demand is reduced unless the implied increase in demand for future goods by savers is effectively transmitted to the entrepreneurs. In the absence of an effective price signal to devote a greater proportion of current resources for capital accumulation, the unemployment state emerges and persists.

27 Ibid., pp. $409-416$. 
Complicating the adjustment process are (1) widely held non-homogenous inflation expectations, (2) the overhang of the threat of yet another bout with an incomes policy, (3) the putty-clay nature of capital which dampens the speed of adjustment toward new relative prices of capital and labor, and (4) an observed increase in the supply of labor induced by wealth and other effects. An additional factor which complicates and lengthens the adjustment in relative prices of capital and labor is the existence of indexed wage contracts, which became more prevalent as the legacy of previously unforeseen inflations. If labor bargained in terms of the real wage that prevailed in the wealthier period, the full equilibrium adjustment would not be obtained until the economy attains the previous wealth and capital intensity level via capital accumulation.

Given the diagnosis of wealth loss due to capital obsolescence, the case for policy actions which accelerate the rate of capital accumulation appears compelling. Unfortunately, such permissive policies may cause a delay in the market adjustment process. Stimulative policies might be interpreted as harbingers of either greater inflation, the imposition of an incomes policy, or both. But such possibilities would always exist in this uncertain world. So the central policy issue is, as always, a Bayesian one of constructing a useful state-and-time dependent decision matrix and assigning the best state-of-the-arts probability weights to state-and-event-spaces. 28 The task of assigning

${ }^{28}$ For the Bayesian approach to decision-making under uncertainty, see H. Raiffa and R. Schlaiffer, Applied Statistical Decision Theory (MIT Press, 1961); also Fox et a1., op. cit., Chapter 9. 
utility weights to event-spaces would be that of the policymaker.

The requirements for an effective policy sketched above appear to demand an impossible prescience of the economist-advisor. Since the source of difficulty is our ignorance of the precise nature of the state and structure of the economy (inclusive of the error structure), it may be inferred that there is little that the economist can contribute. However, such an inference is unwarranted. Absence of precise quantitative or even qualitative knowledge ${ }^{29}$ does not entitle one to invoke the principle of insufficient reason. Rather, it forces one to recognize the limited scope for discretionary stabilization policies. As a consequence, the focus is directed once again to the question fundamental to macroeconomic theory - namely, to what extent can the decentralized, real-world economy be regarded as a self-adjusting system?

This question was forcefully raised by keynes in 1935, and reopened in 1969 by Leijonhufvud in his apt paraphrase of a question posed by a microbiologist: ${ }^{30}$

29 We have not yet resolved such fundamental qualitative issues as the time- and/or policy-invariance of the parameters of the estimated model. See, for example, R. Lucas, "Econometric Policy Evaluation: A Critique," Journal of Monetary Economics (Supplement 1976).

303 . Keynes, "A Self-Adjusting Economic System?" The New Republic (February 20, 1935); A. Leijonhufvud, Keynes and the Classics: Two Lectures on Keynes' Contribution to Economic Theory (The Institute of Economic Affairs, JuTy 1969). 
"An economy (organism) is an integrated unit of structure and functions. In an economy (organism), all transactors (molecules) have to work in harmony. Each transactor (molecule) has to know what the other transactors (molecules) are doing. Each transactor (molecule) must be able to receive messages and must be disciplined enough to obey orders. How has the economic system (organism) solved the problem of inter-transactor (molecular) communication?"

The importance of price information and price incentives as signals and disciplines in the coordination of activities of decentralized transactors is clearly captured in this paraphrase. The significance of questioning the homeostatic capacity of the economy is that it forces the analysis into an explicit general systems perspective, where time, history, and uncertainty play essential roles. It leads one to reexamine the theoretical and empirical foundations underlying various approaches to stabilization policies. Such a reexamination reveals that different approaches are based on different diagnoses of: (1) the dynamic properties of a particular economy, such as its stability, speed and amplitude of response, observability and controllability, and (2) the attained (or attainable) state of the arts in quantitative macroeconomic policy. Consider the following alternative concepts of stabilization policy: 31

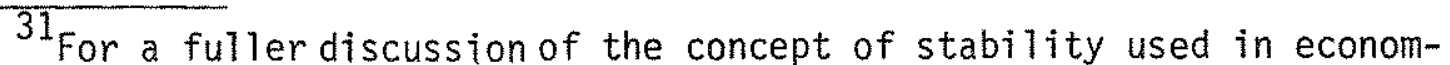
ics and the alternative concepts of stabilization policy, see L. Andersen and $J$. Yang, 'The Economy as a Control System: Implications for "Inherent" Stability Issue," in Modeling and Simulation, Volume 5 Part 2 (Instrument Society of Americ $\bar{a}, 1974$ ) and $\mathrm{J}$. Yang, "The Inherent (In) stability of the Econony: An Interpretation," (unpublished paper, 1975). 
1. The economy is unstable; hence, it must be made stable. Since stability is a concept associated with the nature of response of a given dynamic system to a given stimulus, the objective of the stabilization policy is to change the response characteristics of the system. Such a policy would be a subset of a socalled structural policy;

2. The economy is inherently stable but its speed of adjustment is unsatisfactory. The aim of policy again is to change the nature of the system's response to a given stimulus;

3. The nature of the response of the system to a shock is satisfactory. The root cause of difficulty lies, however, in the nature of disturbances impinging on the system. The thrust of policy is to neutralize the effects of such disturbances. Such a policy may be termed "purely compensatory" and its successful implementation limited only by our ability to forecast the arrival of shocks, and to neutralize them;

4. The quality of response of the economy to different sources and/or magnitudes of shocks is not uniform. It is useful to classify shocks along policy and non-policy origins and the former into monetary and non-monetary lines. The aim of monetary stabilization policy is the avoidance of policy-induced monetary shocks. Here, shocks are to be construed as "innovations" in the given time series.

These various concepts of stabilization policy provide a framework to assess different approaches to stabilization policy. Such approaches range all the way from Simon's constant money supply rule to the optima1 
feedback control with stochastic time-varying coefficient model. 32

The recent rediscovery of the optimal control framework (pioneered by Ramsey in the 1920s) for stabilization policy has had the salutary effect of redirecting our attention to the fundamental normative and positive issues involved in policymaking. In this framework, policy decision problems are explicitly acknowledged as Bayesian and intertempora1. The policy horizon must be explicitly chosen. Uncertainty about the model structure, observational errors, and nonpolicy shocks must also be confronted by the decision maker. Even the problem of stochastic preference could be dealt with, at least formally. The control approach also gives content to the short-run and long-run distinctions, which are often left imprecise.

One may well argue that the control framework blurred the distinction between rule vs. authorities. Even the stochastic feedback control with filtering, which specifies a policy reaction function, may be construed as a form of rule. But, such an interpretation misses the essential distinction that a Rule is characterized by the absence of policy "innovations." In an uncertain world, even if the agents were privy to the same information set and the control law guiding the monetary authority, ex post evolution of policy will have "innovations" reflecting either the model or exogenous non-policy shocks.

${ }^{32}$ H. Simons, "Rules vs. Authorities in Monetary Policy," Journal of Political Economy (February 1936); G. Chow, Analys is and Control of Dynamic Economic System (John Wiley and Sons, 1975), also J. Kalchbrenner and P. Tinsley, "On the Use of Optimal Control in the Design of Monetary Policy," Special Studies Paper, Federal Reserve Board (July 1975), 
It is the inevitable lot of a decision maker to act, even in the presence of uncertainty. Acquisition of knowledge helps us to reduce uncertainty, but the inadequacy in the current state of our knowledge of both the model and error structure of the economy is considerable. The recent explorations into the potential role that modern optimal control theory could play in the conduct of stabilization policy helped to redirect our attention toward many of the unresolved normative and positive issues in policymaking. Aside from the fundamental problem of choosing the objective functional, the problems arising from delayed observations and the absence of a clearly dominant model have been thrust into the center stage where they properly belong. As a consequence, we have richer and better defined substantive issues to guide further research and base policy deliberations.

Unfortunately for policymakers, the clearest signal to be extracted from this exploration is that modeling the workings of the modern decentralized economy is more like modeling a biological system than an engineering system. The problem of stochastic time-varying coefficients naturally arises in such a context. ${ }^{33}$ In addition, it has been forcefully impressed upon us that expectations must be modeled to understand and "control" economic behavior but the processes determining the formation and revision of expectations are only dimly understood. For

${ }^{33}$ The time-varying parameter models include random-coefficient models and systematically time-varying models, depicting, for example, the motion of guided missiles over space. For many important aspects of modeling and estimating time-varying parameter systems, see the report on a recent symposium on such systems in Annals of Economic and Social Measurement (October 1973). 
example, a prominent explanation of the phenomenon of stagflation runs in terms of divergent price expectations between the consumer and the producer. ${ }^{34}$ The problem is that we do not as yet know how to reliably model and influence these expectations.

Outline of An Optimum Monetary Policy

This diagnosis of the state of the arts, in conjunction with the empirical judgments regarding the inherent stability of the economy, and the sources and effects of shocks, suggests an outline of the "optimum monetary policy" for stabilization. ${ }^{35}$ Stabilization must be construed as the effect of policy which permits an approximation to a fuTly coordinated solution characterized by the absence of excess demands and excess supplies in a 11 markets.

First, the optimum monetary policy must be an accomodative policy in the ultimate sense of permitting, more efficiently than any other feasible policy, a futl coordination of temporal and intertemporal plans of decentralized transactor units. Second, given the observations that

${ }^{34}$ K. Brunner and A. Meltzer, "Introduction," Journal of Monetary Economics (Supplement 1976).

${ }^{35}$ For a fuller discussion of the competing diagnoses of the inherent stability of private enterprise economies, see J. Yang, op. cit. and works cited therein; in particular, see L. Andersen, "The state of the Monetarist Debate" and accompanying "commentary" by K. Brunner and L. Klein in Review, Federal Reserve Bank of St. Loujs (October 1973) and $K$. Brunner's book review of Conference on Econometric Models of Cyclical Behavior, edited by B. Hickman, in Journal of Economic Literature (September 1973), pp. 926-33. 
the money economy is particularly vulnerable to shocks which attenuate the use of "money conventions," the policy must be one that maximizes the probability of preserving money conventions in all planned transactions. 36 Third, the optimum policy must be "surprise-free, in order that monetary policy not constitute an additional shock to which the economy must respond. Subsumed under this requirement is that monetary policy be credible in the sense that an announced change in policy (for whatever reason) is believed. Fourth, the indicator of monetary policy must be chosen such that it is as free of false signals as feasible.

What would be the basis for identifying an empirical proxy for such a policy? The basis must be the accumulated understanding of the role which money and the price system play in coordinating the intertemporal consumption and production plans of decentralized decision units. The major elements of such understanding are:

1. Unanticipated inflations generate false trading and distribution effects. Mill and Fisher understood this, whereas the inflationists of the Birmingham School did not. 37

${ }^{36}$ For the concept of money conventions, see A. Hart, Discussion in Proceedings of a Symposium on Inflation: Its Causes, Consequences and Control, edited by S. Rousseas (New York University, 1968), p. 56.

${ }^{37}$ For Mill's surprisingly modern debunking of the inflationist argument (advanced by the Birmingham currency school) essentially in terms of the distinction between anticipated and unanticipated inflation, see J. S. Mi11, Principles of Political Economy (Reprints of Economic Classics: Augustus M. Kelley, 1961), pp. 550-551; for further references to the Birmingham school advocacy, see J. Viner, Studies in the Theory of International Trade (Harper \& Brothers Publishers, 1937), p. 281 and Lord Robbins, The Theory of Economic Development (MacMilian, 1968), $p$. 134. Fisher made a clear distinction between the effects of the antici(continued) 
2. Inflation expectations, when present, are most likely to be non-uniformly held. Such expectations inhibit the formation of futures contracts, in loan and employment, defined in fixed monetary units. The function of money as the standard of deferred payments is attenuated and, as a consequence, the use of a money convention in evaluating futures contracts is discouraged.

3. Even the polar case of perfectly (uniformly and correctiy) anticipated inflation has undesirable consequences. While it is a useful concept for some theoretical inquiry, its occurrence is not likely to be significant empirically.

4. Inflation expectations are not generated randomly, nor are they sustained in the absence of accommodating growth in the money supply.

5. Once inflation expectations are generated and incorporated in loan and wage contracts, vested interests would emerge to oppose the subsequent monetary evolution which would falsify the embodied inflation expectations. The reason that inflation expectations appear to decay slowly is that actual inflations tend to keep pace to validate the prevailing expectations.

37 (continued)

pated and unanticipated inflation, as illustrated in the following quotation: "...the real evils of changing price levels do not lie in these changes per se, but in the fact that they usually take us unaware. It has been shown that to be forewarned is to be forearmed, and that a foreknown change in price levels might be so taken into account in the rate of interest as to neutralize its evils," See I. Fisher, The Purchasing Power of Money, (Reprints of Economic Classics: Augustus M. Kelley, 1963), p. 321. 
6. Indexing of time contracts generates problems of its own, especially with supply-induced shocks. ${ }^{38}$

7. The concept of the optimum supply of money, or optimum rate of inflation, can only be defined relative to the attainable or effective global production possibility frontier. The "notional" global production possibility frontier is not attainable in the presence of transactions costs. The optimum money supply enables the attairment of the outer-most frontier inside the notional frontier, for any given financial technology. The reason is that, for a given financial technology, the optimum money maximizes the extent of specialization by minimizing the broadly-conceived transactions costs, ${ }^{39}$

8. The distinctions between higher prices and rising prices on the one hand, and rising prices and a rise in inflation expectations on the other are seminal distinctions for understanding

${ }^{38}$ A problem of "over-exhaustion" of the total product may emerge with an unanticipated reduction in the economy's productive capacity. For the problem associated with a transition into a regime of complete1y indexed economy, see J. Yang, "The Case for and Against Indexation: An Attempt at Perspective," Review, Federal Reserve Bank of St. Louis (October 1974), especially $\mathrm{pp} .3$ and 6 ; also M. Friedman, "Monetary Correction," in Essays on Inflation and Indexation (American Enterprise Institute for Public Policy Research, 1974), especially p. 45.

${ }^{39}$ For a survey of the state of the arts, including references, related to "the new microfoundations of money," see R. Barro and S. Fischer, "Recent Developments in Monetary Theory," Journal of Monetary Economics (Apri1 1976). 
monetary phenomena. 40

Fisher, and Marshall before him, considered the property of an ideal monetary policy from the perspective of intertempora] coordination through the price system. Both prescribed a policy directed toward securing both ex ante and ex post stability in the monetary yardstick. ${ }^{41}$ Their prescription is consistent with the broad contours of the roles of money and the price system summarized above. They proposed the adoption of indexation, the tabular standard, to achieve their stability goal. Without the use of indexing, however, it would be difficult to achieve ex post stability continuously.

Since there are problems with indexing, and more fundamentally, because achieving ex ante stability would be sufficient to approximate ideal policy, my suggestion for an empirical proxy to the "optimum" policy outlined above would have two elements: First, specify a monetary aggregate as the indicator of policy on the relative controllability basis; second, direct the policy consistently toward the prevention of the emergence of inflation expectations. For a growing economy on a balanced growth path without technological progress, such a policy would

40 The various diagnoses of the causes of inflation in terms of the variants of market power hypotheses (such as the union monopoly or administered pricingloften do not make the distinction between higher and rising prices. The second distinction between the unanticipated and anticipated inflation is, of course, of pivotol importance.

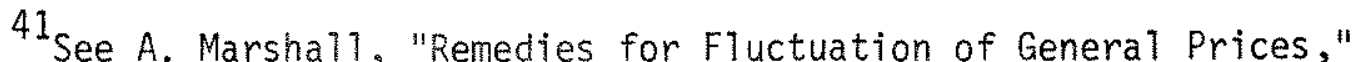
in Memorials of Alfred Marshal1, edited by A. Pigou (New York: Kelly and Millman, Inc., 1956); I. Fisher, Stabilizing the Dollar (New York: MacMillan, 1920). 
aim at providing nominal money stock growing at the natural rate. ${ }^{42}$

\section{Conclusions}

This paper identifies the sources of the widespread concern about capital formation, primarily to uncover those aspects which monetary policy may successfully address. It has been shown that the usual focus is on the nonneutral effect of monetary policy on capacity output rather than the more intractable and speculative possibility that monetary policy may be nonneutral with respect to equilibrium capital intensity.

The proper framework in which to assess the impact of monetary policy on capital formation was judged to be intertemporal and, under uncertainty, Bayesian. Several concepts of the role of stabilization policy were explored, and different approaches to such a policy, ranging from Simon's constant money rule to the modern stochastic optimal control, were considered. The problems of formulating a policy were illustrated for a particular diagnosis of the genesis of the current economic malaise.

The outline of an optimum monetary policy was given in terms of an absence of policy innovations, for a world where uncertainties about observations, expectations, and model and error structures dominate. The perspective maintained throughout was that of coordinating intertemporal decisions through the market system. After briefly identifying the major elements of the accumulated evidence regarding the roles of

\footnotetext{
${ }^{42}$ To help implement such a policy for a growing economy, where capital intensities, the rate of population growth and technologies change, poses a severe challenge to the economist-advisor.
} 
money and the price system, an empirical proxy for the optimum monetary policy was specified in terms of the money supply and directed toward preventing the emergence of inflation expectations. 